\title{
A realistic telecommunication model for electromagnetic transient simulations and control assessment of multi- terminal VSC-HVDC networks in PSCAD/EMTDC
}

\author{
Document Version \\ Final published version
}

Link to publication record in Manchester Research Explorer

Citation for published version (APA):

Carmona Sanchez, J., Green, P., Barnes, M., \& Marjanovic, O. (2019). A realistic telecommunication model for electromagnetic transient simulations and control assessment of multi-terminal VSC-HVDC networks in PSCAD/EMTDC. Paper presented at IET AC/DC Conference, Coventry, United Kingdom.

\section{Citing this paper}

Please note that where the full-text provided on Manchester Research Explorer is the Author Accepted Manuscript or Proof version this may differ from the final Published version. If citing, it is advised that you check and use the publisher's definitive version.

\section{General rights}

Copyright and moral rights for the publications made accessible in the Research Explorer are retained by the authors and/or other copyright owners and it is a condition of accessing publications that users recognise and abide by the legal requirements associated with these rights.

\section{Takedown policy}

If you believe that this document breaches copyright please refer to the University of Manchester's Takedown Procedures [http://man.ac.uk/04Y6Bo] or contact uml.scholarlycommunications@manchester.ac.uk providing relevant details, so we can investigate your claim.

\section{OPEN ACCESS}




\title{
A Realistic Telecommunication Model for Electromagnetic Transient Simulations and Control Assessment of Multi-Terminal VSC-HVDC Networks in PSCAD/EMTDC
}

\author{
Carmona-Sanchez, $J^{*}$, Green, $P R^{*}$, Barnes, $M^{*}$, Marjanovic, $O^{*}$ \\ ${ }^{\star}$ School of Electrical and Electronic Engineering, The University of Manchester, UK \\ carmonaipn@live.com.mx; p.r.green@manchester.ac.uk; mike.barnes@manchester.ac.uk; Ognjen.Marjanovic@manchester.ac.uk
}

Keywords: Telecommunications, switched packet telecommunication systems, jitter, latency, HVDC, Multiterminal Network.

\begin{abstract}
A telecommunication system is vital for the operation and control of large electric power systems such as present and future multi-terminal HVDC networks. The latency in data transmission, and the variation in latency, known as jitter, are one of the most important features, in addition to reliability and security, to be considered in the modelling of telecommunication networks when assessing the overall performance of electric power systems. Further, in switched packet telecommunication systems, such as the internet, data packets arriving out of order might occur. Based on the behaviour of switched telecommunication networks and considering the latency as the main component to be represented, in this paper, a telecommunication model is developed and a user defined component is built in PSCAD/ EMTDC using the FORTRAN 90 language. Such a model is suitable to represent telecommunication networks with variable and constant latency as well as switched packet telecommunication systems, i.e. the internet and telephone networks. Results obtained from the application of the telecommunication model to the control a multi-terminal VSC HVDC network, interfacing offshore wind power generation, are then presented and discussed in the paper.
\end{abstract}

\section{Introduction}

A basic communication system is composed of a transmitter, a transmission medium and a receiver. The transmitter converts the information to an appropriate form for the transmission medium. The receiver converts the information obtained by the transmission medium to a form suitable for use at the receiving location. The transmission media can be metallic wires (for electric signals), air and space (for radio or microwaves) or optical fibres (for light signals) [1]. A transmission network in a communication system can be basically composed of a sending point (X1), a repeater (X2) and a receiving point (Y1), as shown in Fig. 1. Alternatively, it can be composed of a more complex network such as the switched packet network shown in Fig. 2. Different types of data transmission technologies (fibre optics, radio waves, etc.) interconnecting different points of the transmission network and the participation of a variety of operators typically results

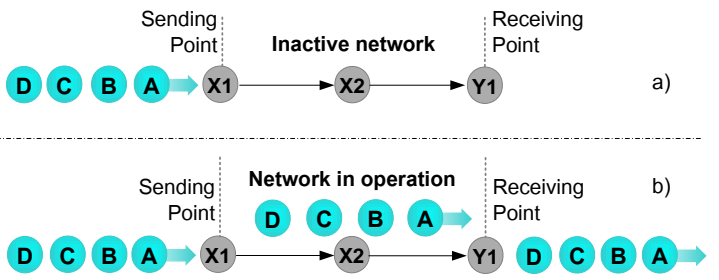

Fig.1: Dedicated-path communication system example. a) Inactive network and b) network in operation.
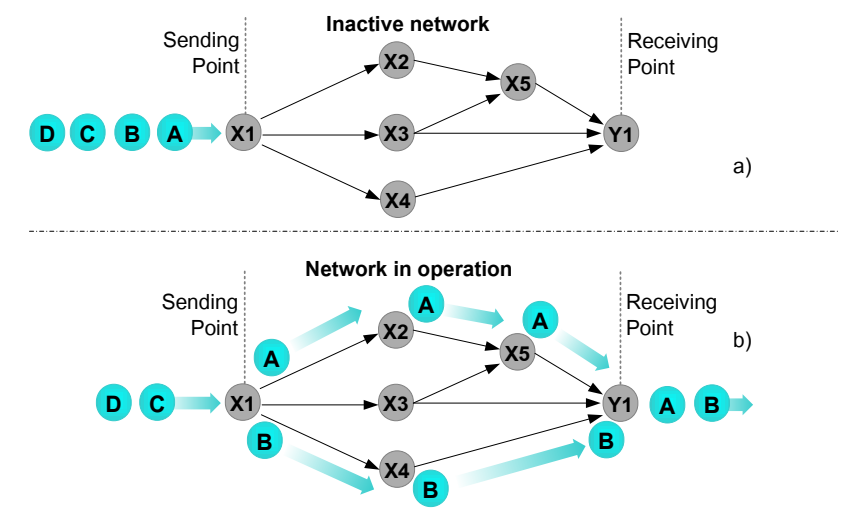

Fig. 2: Switched packet communication network example. a) Inactive network and b) network in operation.

in different delays in a telecommunication system.

The communication architecture has to meet requirements for latency, reliability and security. If a dedicated path is used for the transmission of information, this information would travel through the transmission network in a sequential manner (first-in first-out or FIFO), as shown in Fig. 1b (network in operation). However, the reliability of a communication system can be affected by link failures, routing failures and interference in the physical medium. If different paths are available, data could be sent through these different paths, hence increasing the network reliability. However, this could lead to different delays for the transmission of the information which typically occurs in switched packet networks such as internet and telephone networks. Consider the example given in Fig. 2b (network in operation), if the path defined by $\mathrm{X} 1$, $\mathrm{X} 2, \mathrm{X} 5$ and $\mathrm{Y} 1$ has a longer delay at a given time than the path $\mathrm{X} 1, \mathrm{X} 4$, and $\mathrm{Y} 1$ at another later given time and if packet $A$ is sent through the first path and packet $B$ is sent through the second path, this would lead to B arriving before A. This is one of the main features, apart from the delay itself, to be integrated in telecommunication system models for their use 
in transient and stability analysis of electric power systems such as Multi-terminal (MT) High Voltage DC (HVDC) networks. Additionally, multiple copies of the same message could be sent to their destination, using multiple paths and allowing the different servers to execute the same task, so as to improve network reliability but at the expense of generating more network traffic.

The main problem in simulating telecommunication networks together with power systems is that programs such as PSCAD/EMTDC (used for electromagnetic transient studies) lack dedicated libraries for modelling telecommunication networks. Hence, this problem is usually solved by cosimulation, where the telecommunication system is simulated in one dedicated program and the power system is simulated in another dedicated program [2]-[4]. However, telecommunications (telecoms) simulators are almost all event based whilst analogue simulators, such as PSCAD/EMTDC, are time-step based. Hence, the synchronization between these two types of simulators is the main problem when using co-simulation. A second solution is the integration of the telecommunication model in the power system simulator. By doing this, the synchronization problem between simulators is removed. This second solution is the one presented in this paper and has been implemented in PSCAD/EMTDC.

\section{Telecommunication Model}

The variation in latency, i.e. jitter, is one of the most important features, apart from network reliability and security, to be considered for telecommunication network simulations in the assessment of electric power systems. Based on the behaviour of switched telecommunication networks and considering the latency as the main component to be represented in the telecommunication model, a user defined component was built in PSCAD/EMTDC using the FORTRAN 90 language. The main components of this model are exemplified in Fig. 3-4. The telecommunication model provides the most recent data considering the time delay the data would experience through the communication network. The FORTRAN 90 code, given in [5], is executed as follows:

1. The signal to be transmitted is sampled (i.e. Input data in Fig. 3-4) at a frequency specified by the sampling frequency (i.e. "Ssamf" in Hertz). The sampling frequency is a parameter which is specified at the beginning of the simulation but it can be modified during execution of the simulation as well.

2. At the time that the signal is sampled, a data transmission time delay (Td) is assigned to the sample. This time delay mimics the time that the data would take, in reality, to travel through the communication network.

3. The sample of the signal, the time at which it was sampled (timestamp) and the future time at which the signal will be the output of the telecommunication network (timestamp plus delay time) are written to a buffer. Table 1 exemplifies the buffer structure and gives some numerical examples. A pointer is also

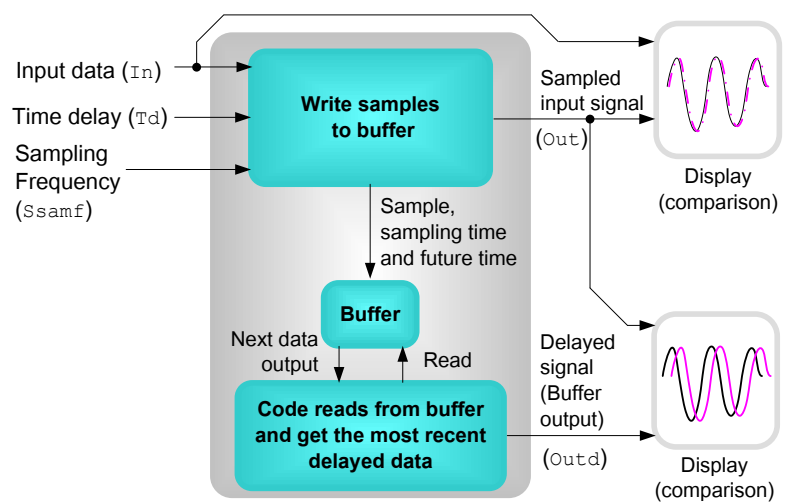

Fig. 3: User defined component for modelling telecommunication systems in PSCAD.

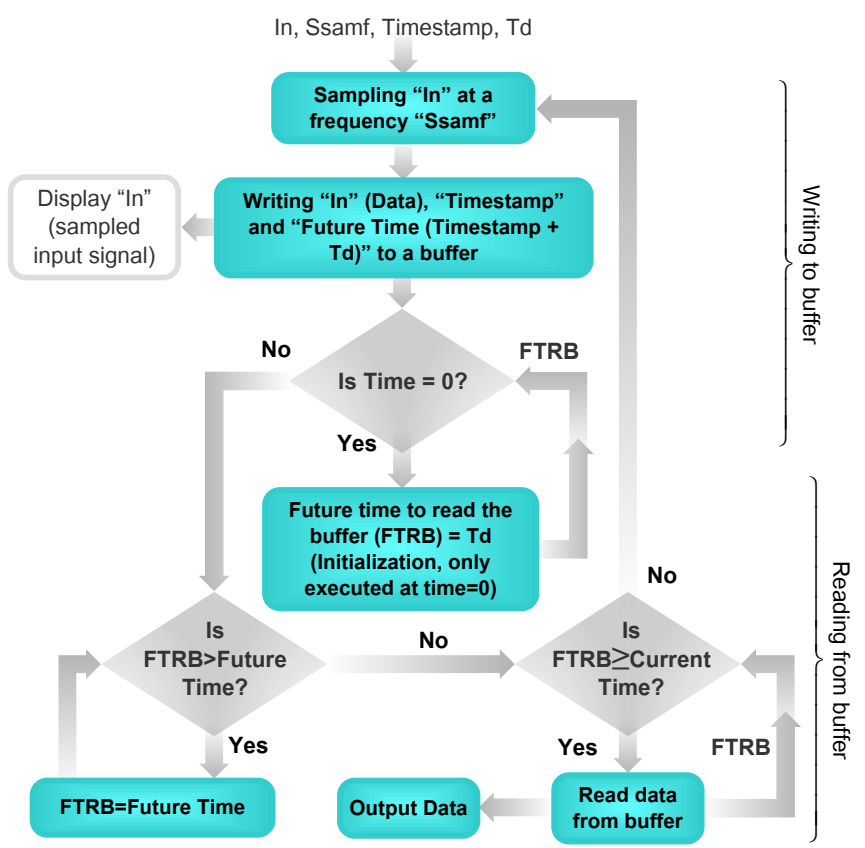

Fig. 4: Flowchart for modelling telecommunication networks in time-step based programs.

specified for every sample to indicate the place of the sample in the buffer. The buffer is a file which is located in the hard disc of the PC. RAM memory could also be used for such a purpose. In the example presented in Table 1, the delay varies on a sample by sample basis as can be observed for sample D. The time delay values that are fed to the model, i.e. Td, could be derived from a statistical distribution of delay values or from the replay of pre-recorded network performance.

4. The values of the sampled signal, apart for being stored in a buffer, are continuously displayed for analysis purposes (e.g. comparison with the original signal). This is "Sampled input signal" in Figs. 3-4.

5. When the first sample is read (at the beginning of the simulation), the time at which the signal will be the output of the telecommunication network is taken as the future time to read the buffer (FTRB), as shown in Fig. 4. Every time a sample is taken, its future time is compared against the time at which the buffer will be read (FTRB), Fig. 4. If the new incoming sample has 


\begin{tabular}{c|c|c|c|c|c|c|c}
\hline \multicolumn{7}{|c|}{ Buffer } \\
\hline $\begin{array}{c}\text { Sampling } \\
\text { Time (s) }\end{array}$ & $\begin{array}{c}\text { Data } \\
\text { (sample) }\end{array}$ & \multicolumn{5}{|c}{ Future Data Output Times (s) } & Pointer \\
\hline & & Timestamp & \multicolumn{2}{|c|}{$\begin{array}{c}\text { Time } \\
\text { Delay } \\
\text { (Td) }\end{array}$} & & & \\
& & & & & \\
\hline 1.005 & A & 1.005 & + & 0.065 & $=$ & 1.070 & 1 \\
\hline 1.010 & B & 1.010 & + & 0.065 & $=$ & 1.075 & 2 \\
\hline 1.015 & C & 1.015 & + & 0.065 & $=$ & 1.080 & 3 \\
\hline 1.020 & D & 1.020 & + & 0.040 & $=$ & 1.060 & 4 \\
\hline$*$ & $*$ & $*$ & + & $*$ & $=$ & $*$ & $*$ \\
\hline$*$ & $*$ & $*$ & + & $*$ & $=$ & $*$ & $*$ \\
\hline$*$ & $*$ & $*$ & + & $*$ & $=$ & $*$ & $*$ \\
\hline 1.060 & $\mathrm{~L}$ & 1.060 & + & 0.065 & $=$ & 1.125 & 12 \\
\hline
\end{tabular}

Table 1: Buffer structure for the emulation of the telecommunication network and numerical examples.

a newer time than the previous specified time at which the buffer would be read, then this newer time is taken as the next time to read the buffer, hence the previous sample is bypassed by the new sample. This feature of the code is essential for modelling switched packet telecommunication systems and this functionality is exemplified with the aid of Fig. 5. Further explanation is given below.

6. When the time to read the buffer is reached, the code opens the buffer and reads the sample corresponding at that time, Fig. 4. The next time to read the buffer is updated by reading the future time of the next sample in the buffer. Subsequently, the code inspects the remainder of the buffer to check if there is a newer time within the buffer to read the buffer. If so the next time to read the buffer is updated.

As mentioned before, essentially what the telecommunication model does (Fig. 3-4) is to provide the most recent data considering the time delay the data would experience through the communication network. To illustrate this consider the examples given in Table 1 and Fig. 5, when the simulation time is $1.060 \mathrm{~s}$, the code reads the data " $\mathrm{L}$ " and writes it to the buffer. At the same time the code outputs the data "D". This is because data " $\mathrm{D}$ " has experienced a much smaller latency (delay) through the telecommunication network and it is also newer data in comparison to " $\mathrm{A}$ ", " $\mathrm{B}$ " and " $\mathrm{C}$ ". Hence it is taken as output of the telecoms. Furthermore, in Fig. 5, it can be observed that the signal can be distorted if variable time delays are present within the network. To further illustrate this, the telecommunication model was tested in PSCAD with results given in Fig. 6. A sinusoidal $50 \mathrm{~Hz}$ sinusoidal signal was used as the input (Input data) to the telecommunication network; this signal was sampled at $500 \mathrm{~Hz}$ (sampled input signal). Whilst, it is unlikely that the telecoms network would be used to transmit the samples of a sinusoidal waveform, the example illustrates the effect of delay. A time delay profile was generated, as shown at the bottom of Fig. 6, and was used to delay the sampled input signal. As can be seen in Fig. 6, when the time delay varies, the final signal output from the telecommunication system stretches as the time delay increases gradually. When there is a constant time delay, the signal just suffers a phase shift as expected.

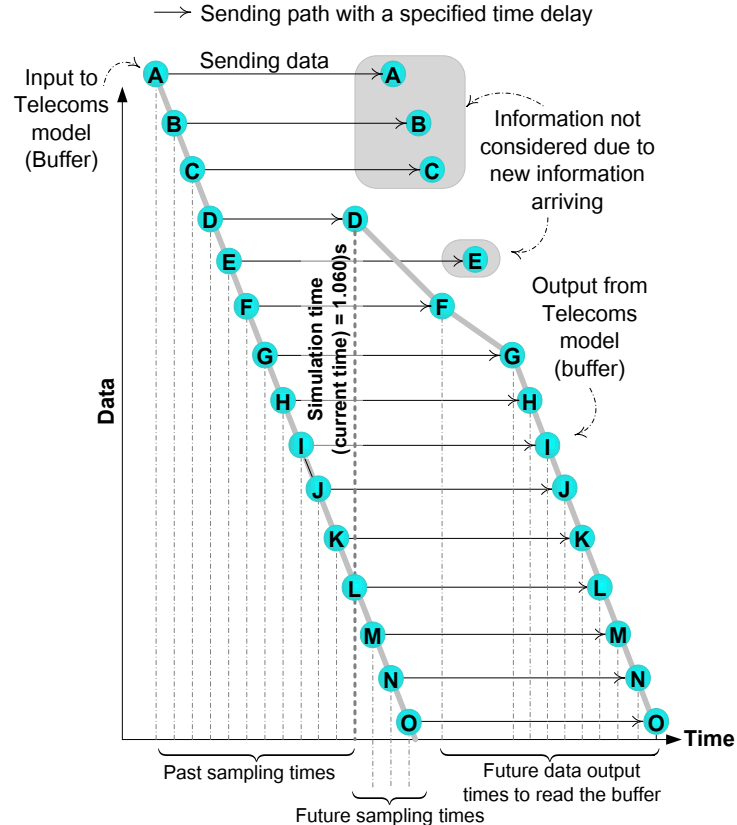

Fig. 5: Disregarded data in switched telecommunication network due to new data arriving.

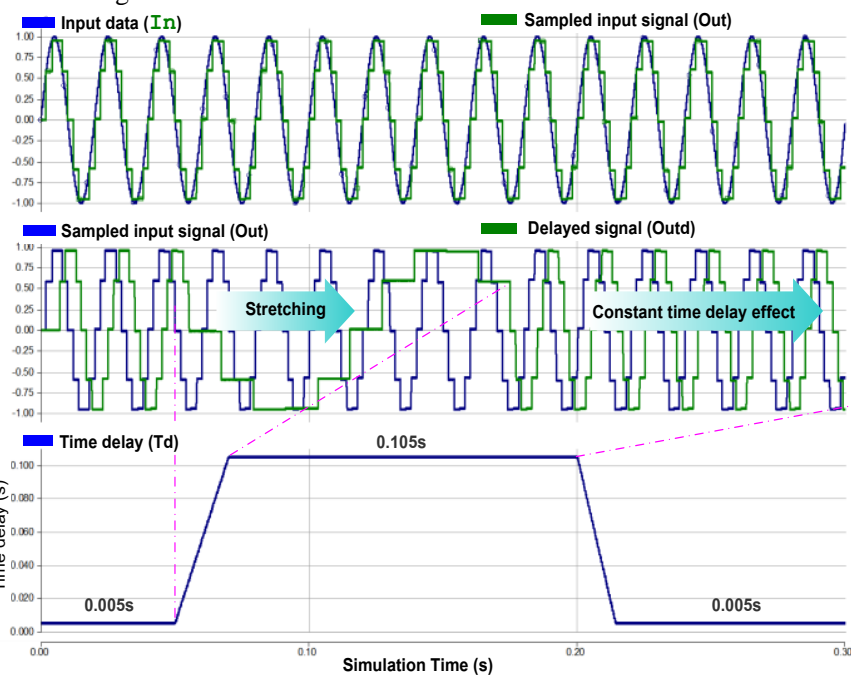

Fig. 6: Simulation results for the telecommunication model, shown in Figs. 3 4 , for a variable time delayed signal.

Results obtained from the application of the telecoms model to the control a multi-terminal VSC HVDC network are given in the next sections of the paper.

\section{Case Study - Six-Terminal VSC-HVDC Network}

The six-terminal VSC-HVDC network shown in Fig. 7 is considered in this paper. This MT HVDC network is based on the DC configuration of the Northern section of the Atlantic Wind Connection (NAWC). It has been built on publicly available information as given in [6] and [7]. Offshore wind turbines generate medium-voltage $\mathrm{AC}$ power, which is collected and transformed to higher-voltage AC power. The AC power is converted to DC power and transmitted by means of a low-loss DC current transmission system. Finally, the transmitted DC power is converted back to AC and 


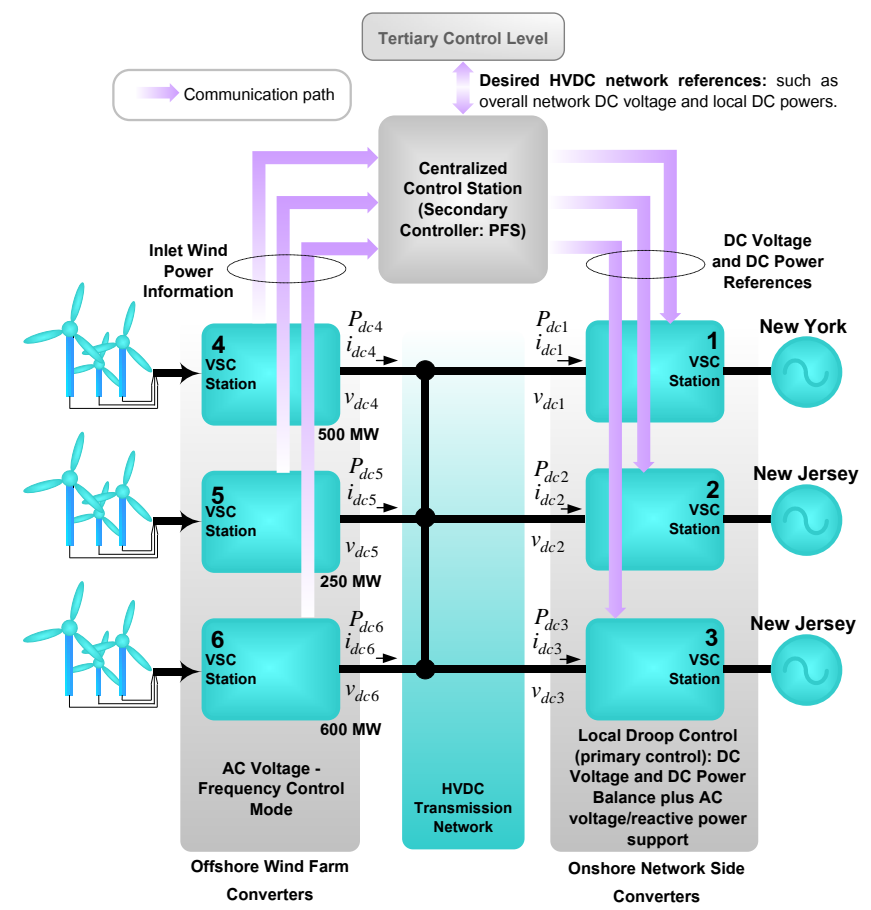

Fig. 7: Six-terminal VSC-HVDC test-system interconnecting offshore power generation to onshore grid. Please, refer to [7]-[8] for detailed descriptive information of this system.

distributed to the onshore AC grid. It is assumed that the NAWC would employ Modular Multilevel Converts (MMC) based on Half-Bridge submodules (HB). A Power Flow Solver (PFS), a type of multivariable control, is used as the centralized secondary controller to deal with the power flow and DC voltage control of the system. The mathematical model of the system is given in [8] and the detailed control architecture design of the secondary centralized controller is given in [7].

\section{a) Telecommunication Configurations and Technologies for Benchmarking of the Six-terminal HVDC Test- System}

The operation of offshore converter substations is normally performed remotely, from onshore [9]. Hence, from the point of view of maintenance and reliability, the secondary grid controller should be physically located onshore, ideally in an onshore converter Station. Submarine HVDC cables are usually integrated with optical fibre [10]. Hence, the sixterminal HVDC system is more likely to have, under normal operation, a dedicated fibre-optic communication network, such as the one shown in Fig. 8a. Based on the structure of this communication network and the distances between Stations, one of the best options for the location of the secondary controller is Station number 2 . For this configuration, if links between Stations 4-5 and/or 4-1 develop a fault, the secondary controller can still communicate with Station 3. If links between Stations 5-6 and/or 3-6 develop a fault, the secondary controller can still communicate with Station 1. This fibre-optic communications network is considered as "Telecommunications Option 1" in Table 2.

Submarine HVDC cables could suffer damage due to
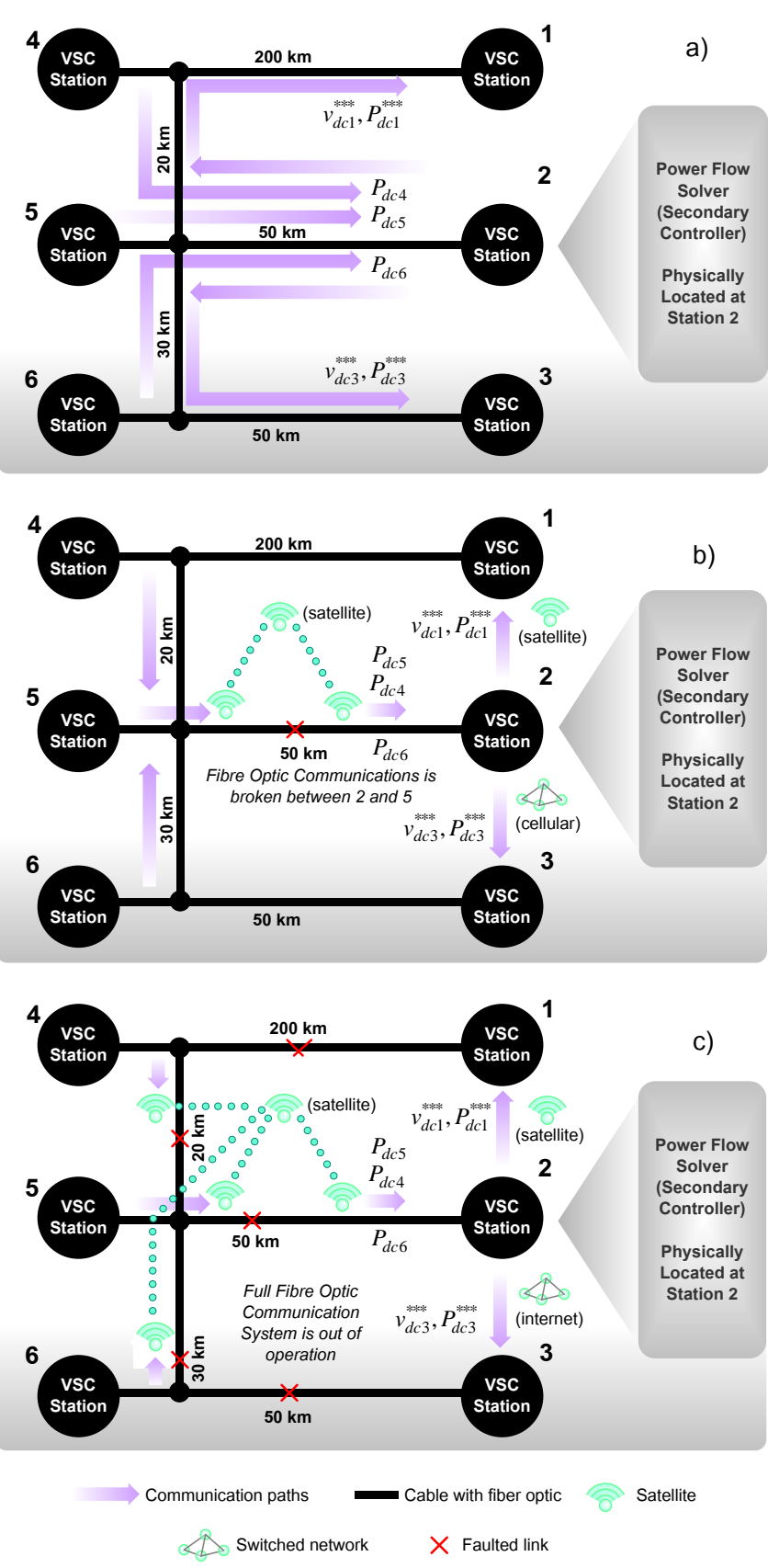

Fig. 8: Telecoms options for the Six-Terminal HVDC system: a) Option $1-$ fibre optic telecommunication network, b) Option 2 (Backup 1) - mixed technologies -and c) Option 3 (Backup 2) - mixed technologies.

different factors such as tidal currents, fishing and ships dragging their anchor. This in turn could also adversely affect their internal optical fibres, causing degradation or complete loss of the communication channel. Additionally, faults in the optical/electrical interface (i.e. communication channels to computer systems) are a possibility. Hence, if the link between Stations 2 and 5 develops a fault, the secondary controller would be lost since no information would be received from the offshore converters (i.e. powers $P_{d c 4}, P_{d c 5}$ and $P_{d c 6}$ ) nor commands (i.e. $v_{d c 1}^{* * *}, P_{d c 1}^{* * * *}, v_{d c 3}^{* * *}$ and $P_{d c 3}^{* * *}$ ) would be sent to the other two onshore Stations (1 and 3). Duty cycles for converters in utility power industries are 


\begin{tabular}{|c|c|c|c|c|c|c|c|}
\hline \multirow{2}{*}{$\begin{array}{l}\text { Connected } \\
\text { Stations }\end{array}$} & $\begin{array}{l}\text { Telecoms } \\
\text { Option } 0\end{array}$ & \multicolumn{2}{|c|}{$\begin{array}{c}\text { Telecoms Option } 1 \\
\text { (normal operation, Fig. 8a) }\end{array}$} & \multicolumn{2}{|c|}{$\begin{array}{l}\text { Telecoms Option } 2 \\
\text { (Backup 1, Fig. 8b) }\end{array}$} & \multicolumn{2}{|c|}{$\begin{array}{l}\text { Telecoms Option } 3 \\
\text { (Backup 2, Fig. 8c) }\end{array}$} \\
\hline & \multirow{6}{*}{$\begin{array}{c}\text { Perfect } \\
\text { Communications } \\
\text { (No delay, unrealistic } \\
\text { but commonly } \\
\text { used for the } \\
\text { assessment of electric } \\
\text { power systems) }\end{array}$} & Technology & Latency & Technology & Latency & Technology & Latency \\
\hline $2-1$ & & Fibre Optic & $\begin{array}{l}1.35 \mathrm{~ms} \\
\text { (constant) }\end{array}$ & Satellite & $\begin{array}{l}900 \mathrm{~ms} \\
\text { (constant) }\end{array}$ & Satellite & $\begin{array}{c}0.9 \mathrm{~s} \\
\text { (constant) }\end{array}$ \\
\hline $2-3$ & & Fibre Optic & $\begin{array}{c}0.65 \mathrm{~ms} \\
\text { (constant) }\end{array}$ & Cellular & $\begin{array}{c}60 \mathrm{~ms} \\
\text { (constant) }\end{array}$ & Internet & $\begin{array}{c}1.68-1.92 \mathrm{~s} \\
\text { (variable as given } \\
\text { by Fig. 9)* }\end{array}$ \\
\hline $2-4$ & & Fibre Optic & $\begin{array}{c}0.35 \mathrm{~ms} \\
\text { (constant) }\end{array}$ & Fibre Optic + Satellite & $\begin{array}{c}900 \mathrm{~ms} \\
\text { (constant) }\end{array}$ & Satellite & $\begin{array}{c}0.9 \mathrm{~s} \\
(\text { constant })\end{array}$ \\
\hline $2-5$ & & Fibre Optic & $\begin{array}{c}0.25 \mathrm{~ms} \\
\text { (constant) }\end{array}$ & Satellite & $\begin{array}{c}900 \mathrm{~ms} \\
\text { (constant) }\end{array}$ & Satellite & $\begin{array}{c}0.9 \mathrm{~s} \\
\text { (constant) }\end{array}$ \\
\hline $2-6$ & & Fibre Optic & $\begin{array}{l}0.40 \mathrm{~ms} \\
\text { (constant) }\end{array}$ & Fibre Optic + Satellite & $\begin{array}{l}900 \mathrm{~ms} \\
\text { (constant) }\end{array}$ & Satellite & $\begin{array}{c}0.9 \mathrm{~s} \\
\text { (constant) }\end{array}$ \\
\hline & \multirow[t]{2}{*}{ Comments } & \multicolumn{2}{|c|}{$\begin{array}{l}\text { This telecoms option is expected } \\
\text { to be inherent to the HVDC } \\
\text { network design. }\end{array}$} & \multicolumn{4}{|c|}{$\begin{array}{l}\text { From a faster to a slower telecommunication option (Telecoms Option } 2 \text { to } \\
\text { Telecoms Option 3). See [12] and [13] for more detailed information on } \\
\text { telecoms. }\end{array}$} \\
\hline & & & & \multicolumn{4}{|c|}{$*$ Data adapted from $[13]$} \\
\hline
\end{tabular}

Table 2: Telecommunication Configurations and Technologies for Benchmarking of the Six-terminal HVDC Test-System.

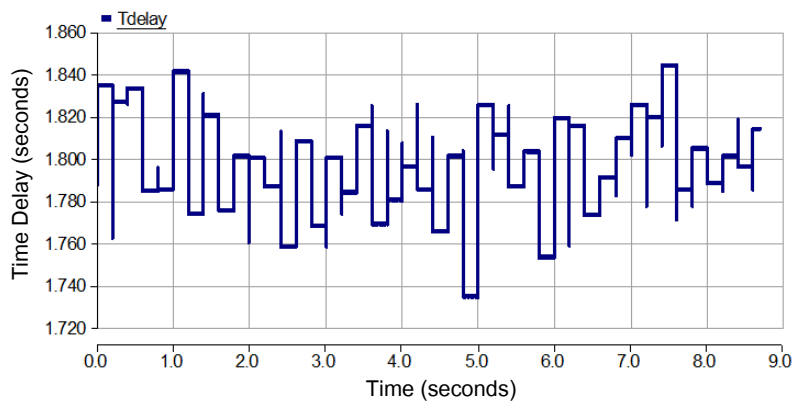

Fig. 9: Variable time delay used for the simulation of the internet in the benchmarking of Telecoms-Option 3 .

typically 365 days/24 hours, which implies a need for a very high reliability level [11]. Hence, from the reliability and availability point of view, it is highly desirable to have a backup communication system in place. Commercial wireless communication systems (e.g. satellite, cellular) or switched communication networks (e.g. internet) could be potential candidates as shown in Fig. 8b. This hybrid communication system is considered as "Telecoms Option 2 (Backup 1)" in Table 2. As a last resort, a second backup communication system (Fig. 8c) could be needed to keep the system working under emergency circumstances. This communication system is considered as "Telecoms Option 3 (Backup 2)" in Table 2. Given the geographical distances between VSC HVDC converter Stations, latency (i.e. delay) in signal transmission is the most important feature (apart from lost and/or corrupted information) to be considered for modelling of telecommunication systems in HVDC network studies. Based on information given in [12] and [13] the communication technologies with latencies given in Table 1 have been selected for the telecommunication configurations shown in Figs.8a-c. In the case of Telecoms Option 3, a variable time delay, as given by Fig. 9, has been used to emulate the Jitter of the internet to communicate between Stations 2 and 3 .

\section{b) Results - Degradation of the control performance of MT HVDC network with the multi-mode telecommunications network in place}

By making use of the advanced telecommunications model presented in Section 2, the degradation of the control performance of the six-terminal HVDC network, due to the quality of service of different telecommunication technologies (as given in Table 2), is assessed in this section. Given the high variability of offshore wind energy, the six-terminal HVDC network, was tested under the following two scenarios:

i. Case $\mathbf{1}$ - Significant increase in Generation: The power injected by VSC Station 5 is increased by $100 \%$ (i.e. it doubles its generation).

ii. Case 2 - Loss of Generation: VSC Station 6 (offshore converter) is lost.

Results for Case 1 are given in Figs. 10 and 11. Fig. 10a shows the time needed for the HVDC network to achieve full steady state operation for Case 1 and for all Telecoms Options given in Table 2. Fig. 11 shows the comparison in transient response, of the HVDC network, for Telecoms Option 1 and 2. At $\mathrm{t}=5 \mathrm{~s}$, a step in mechanical power, i.e. wind power, is applied to the wind farm connected to VSC Station 5. This step results in the corresponding first-order response of the electric active power $\left(P_{d c 5}\right)$, which is transmitted to the HVDC network, as shown in Fig. 11. Although such a rapid power change may not be deemed realistic, it imposes a more critical scenario for the benchmarking of the system and its local Station controls, i.e. DC voltage and droop. In reality, large wind turbines are expected to have a time constant of approximately $15 \mathrm{~s}$ [7], which implies a less challenging, i.e. lower control bandwidth requirement, disturbance scenario to be dealt with by the converters' controls. The secondary controller (PFS) has been designed to deal with the wind power disturbance by maintaining the DC voltage at Station 1 and DC powers at Stations 2 and 3 at their pre-disturbance reference values. Fig. 11 shows that, at least during transient conditions, powers at Stations 2 and 3 deviate considerably from their respective set-points when "Telecoms Option 2" is used instead of "Telecoms Option 1" for the interface between the PFS and local Stations' controllers. "Telecoms Option 2" leads Stations 2 and 3 to absorb more power, hence more energy, for the same transient conditions (Case 1 Significant increase in generation). If for some reason, the 


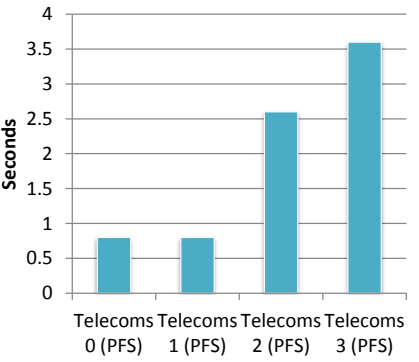

a)

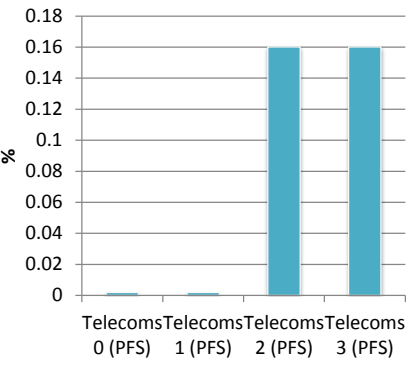

b)
Fig. 10: Significant increase in generation: a) Time to achieve full steady state operation for the HVDC network and b) Maximum percentage deviation from its DC voltage reference for Station 2 under transient conditions.

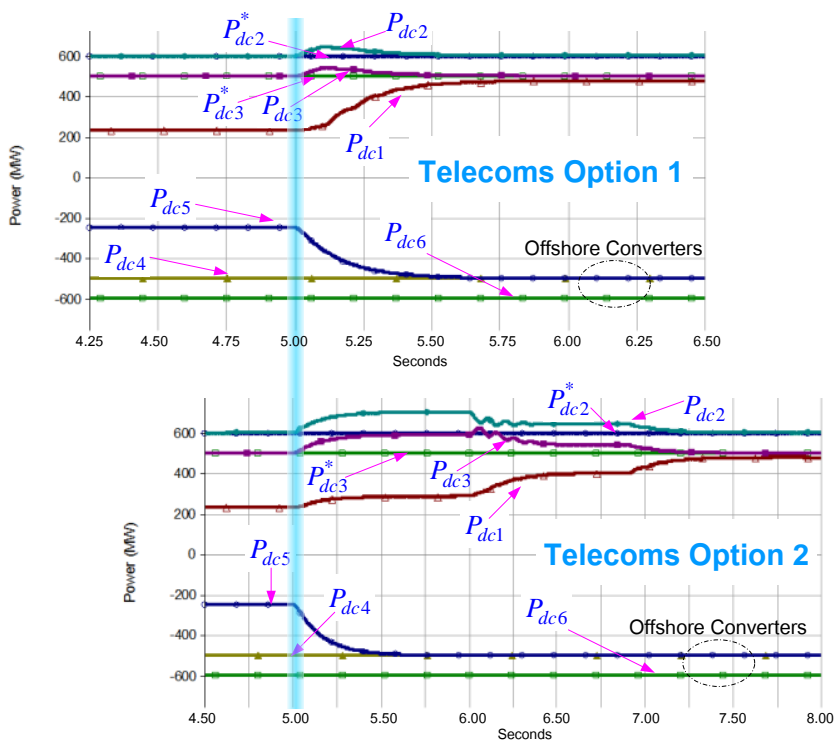

Fig. 11: Power deviations at Stations 2 and 3 from set-points (*) under transient conditions (Case 1) for the six-terminal HVDC network with different telecommunications technologies.

operators of Stations 2 and 3 (which are part of the New Jersey area, Fig.7) were to have the opportunity to use either Telecoms Option 1 or Telecoms Option 2, it is obvious that they would opt for "Telecoms Option 2" since it is the one that would benefit them the most in this particular case.

As can be seen in Fig. 10a, the time needed for the HVDC network to achieve steady state operation, when using an ideal telecoms system (Telecoms Option 0), is almost the same as the one needed when using Telecoms Option 1 (fibre optics). However, the response time differs significantly when the telecoms system in place is composed of satellites, telephone or the internet (Telecoms Option 2 and 3). Further, it was found that the deviation of the DC voltage, under transient conditions, at Station 2 was larger for Telecoms Options 2 and 3 than that obtained for Telecoms Options 0 and 1, as shown in Fig. 10b. Similar results were obtained for Case 2 as shown in Fig. 11.

\section{Conclusions}

Built in fibre-optic submarine HVDC cables could suffer damage due to different factors such as tidal currents, fishing and ships dragging their anchor. Hence, degradation of the fibre-optic telecoms system is a possibility due to a loss of

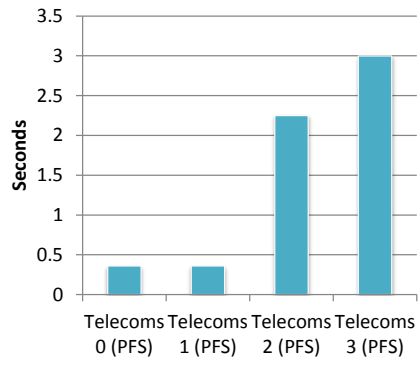

a)

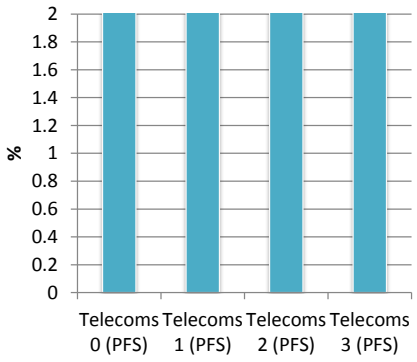

b)
Fig. 11: Loss of generation: a) Time to achieve full steady state operation for the HVDC network and b) Maximum percentage deviation from its DC voltage reference for converter 2 under transient conditions.

one or more telecommunication links. In such circumstances higher latency telecoms technologies (e.g. satellites) could be needed to keep the control of the HVDC network.

Assuming an ideal telecoms system (zero delay) for the assessment of HVDC systems is inappropriate when the actual telecommunication network in place is composed of satellites, cellular or internet networks. Under such circumstances, there could be a significant difference between the time response expected from the HVDC network and the actual HVDC network time response to a command signal. This is particularly important for studies whose objective is to find the time response of the HVDC network to provide ancillary services to its interconnected AC networks (e.g. power-frequency support). Furthermore, the HVDC system could be subjected to higher electrical stresses under transient conditions that could accelerate the aging process of components such as cables, transformers and converters.

\section{Acknowledgements}

This work was supported by the Engineering and Physical Sciences Research Council (EPSRC) through grants EP/P009743/1 and EP/L021463/1.

\section{References}

[1] Electronic Communications Resilience \& Response Group (EC-RRG) "Telecommunications Networks - a vital part of the Critical National Infrastructure". Report, Version 1.1, Accessed 14/08/2018.

[2] V. Liberatore and A. Al-Hammouri, "Smart grid communication and cosimulation," IEEE 2011 EnergyTech, Cleveland, OH, 2011, pp. 1-5.

[3] W. Li, M. Ferdowsi, M. Stevic, A. Monti and F. Ponci, "Cosimulation for Smart Grid Communications," in IEEE Transactions on Industrial Informatics, vol. 10, no. 4, pp. 2374-2384, Nov. 2014.

[4] X. Shi, Y. Li, Y. Cao and Y. Tan, "Cyber-physical electrical energy systems: challenges and issues," in CSEE Journal of Power and Energy Systems, vol. 1, no. 2, pp. 36-42, June 2015.

[5] Fortran Code (developed for the telecoms model presented in this paper), available at: https://pure.manchester.ac.uk/admin/files/76602562/FORTRAN_Code_PSCAD Telecoms_Model_ACDC_Conference_2019.pdf

[6] The Chertoff Group, "Atlantic Wind Connection: Grid Resiliency, Its Economic and Security Impacts, and the Implications of AWC," Company Report, 2012.

[7] A. Beddard, A. Adamczyk, M. Barnes and C. Barker, "HVDC grid control system based on autonomous converter control," IET, PEMD, Glasgow, 2016, pp. 1-6.

[8] J. Carmona Sanchez, O. Marjanovic, M. Barnes and W. Wang. "Comparison of DC Linear and Nonlinear Models for Multiterminal VSC HVDC Networks". PEMD, Liverpool, UK, 17 - 19 April, 2018.

[9] The Crown Estate. 'Transmission infrastructure associated with connecting offshore generation'. Report, UK, 2013.

[10] ABB. "Submarine Power Cables - Cables for offshore wind farms". 2012.

[11] Shaoyong Yang; Bryant, A.; Mawby, P.; Dawei Xiang; Ran, L.; Tavner, P., "An Industry-Based Survey of Reliability in Power Electronic Converters," in Industry Applications, IEEE Transactions on , vol.47, no.3, pp.1441-1451, May-June 2011

[12] OFCOM. "Measuring mobile broadband performance in the UK - 4G and 3G network performance". Research Report, April 2, 2015.

[13] OFCOM. "UK Home broadband performance: The performance of fixed-line broadband delivered to UK residential consumers". Research Report, March 24, 2016. 